revista ANTHROPOLÓGICAS

Ano 21, 28(2): 6-26, 2017

\title{
Olhos Miúdos e Olhos Graúdos em Massacará: a ideologia étnica
}

Edwin B. Reesink ${ }^{\mathrm{a}}$

O texto procura etnografar a terminologia, as identificações e as relações entre caboclos e portugueses, maneira como se denominam regularmente os dois lados em oposição, às vezes conhecidos como indios e civilizados. A etnografia versa sobre o povo indígena Kaimbé no sertão noroeste da Bahia, em Massacará (município de Euclides da Cunha), para o 'tempo etnográfico' de 1976-7. A questão básica concerne a como se relacionam a identificação de si, a identificação pelos outros e o critério de pertencimento étnico pela descendência. Discute-se, então, a partir do fato de ter havido e haver bastantes casamentos interétnicos, se os filhos dos casamentos mistos têm certa margem de manobra em escolher a que lado querem pertencer.

Índios; Kaimbé; Ideologia Étnica; Mistura; Auto-identificação; Alteridentificação.

\section{Prólogo: contextualizando}

Esse artigo, que se propõe a descrever a terminologia, as identificações e as relações entre caboclos e portugueses, maneira como se denominam regularmente os dois lados em oposição na região de Massacará, no município de Euclides da Cunha (BA), é uma tradução revista de uma etnografia inédita em português, e quase inédita em inglês, em função de sua circulação muito restrita,

a Professor Titular do Departamento de Antropologia e Museologia e da Pós-Graduação em Antropologia (UFPE). Email: edwin.reesink@ufpe.br. 
produzida em $1977^{1}$. Trata-se de um texto meu que, quando dessa época da década de setenta do século passado, era um estudante estrangeiro de antropologia, e o escrito deve ser visto nesse contexto e situação histórica. Para se entender melhor a sua relevância, precisa-se explicar minimamente esse contexto histórico.

Em primeiro lugar, baseia-se em uma pesquisa de campo obrigatória, de dois ou três meses no exterior, e que fazia parte do curso de 'antropologia cultural' da Universidade de Leiden. Ou seja, o curso em si se dedicava à antropologia sociocultural desde o ingresso do estudante, algo, diga-se, inexistente no Brasil da época. Segundo, nessa mesma época, Pedro Agostinho liderava o que acabou sendo chamado de Programa de Pesquisa sobre os Povos Indígenas no Nordeste Brasileiro (PINEB), e a minha inserção nesse grupo de pesquisa determinou a escolha do campo em Massacará, sertão da Bahia, entre os Kaimbé (um local próximo dos Kiriri de Mirandela).

Depois da monografia sobre os Kiriri, por parte de Maria de Lourdes Bandeira (1972), também com ajuda e influência de Pedro Agostinho, as dissertações e artigos desses pesquisadores deram início a uma época de pesquisas dentro de uma linha da antropologia contemporânea. Sem entrar em uma análise da antropologia dessa época, vale somente avivar que Roberto Cardoso de Oliveira tinha, quase na mesma época (desde pouco antes de 1970), proposto o estudo dos povos nordestinos, marginalizados na etnologia como um campesinato índígena, e orientou um estudante de mestrado nesse sentido (Paulo Marcos Amorim). Seu esforço pioneiro se dirigiu muito mais para essa dimensão de campesinato, e o 'potencial de integração', e não teve um seguimento sustentado: logo Cardoso começa a sua fase de examinar os conceitos de etnia e grupo étnico. Na década de 70 ainda não se testemunha a grande ascensão que a 'Introdução' de Barth terá no Brasil, mas a mesma já iria inspirar Cardoso de Oliveira nessa década. A proposta do PINEB era, então, mais ampla do que a de Cardoso de Oliveira, e se manteve como um engajamento mais duradouro no Nordeste. A monografia de Bandeira (1972) 
consistia de uma tentativa ampla de etnografia mais clássica (digamos malinowskiana), e a minha pesquisa aqui traduzida se empenhou em seguir nessa mesma trilha. Ao contrário da monografia de Bandeira, a etnografia sobre Massacará não foi publicada e teve uma circulação muito restrita, basicamente só no PINEB. Em função disso o texto é, como dito, na verdade, praticamente inédito.

O fato de tentar descrever e analisar uma ideologia étnica, identificações coletivas, raça e discriminação - por causa do que ficou mais conhecida depois como a 'mistura' - naquele momento histórico, é um retrato muito raro na literatura mais antiga, e até certo ponto, até mesmo na mais contemporânea. A literatura mais antiga certamente precisa ser melhor conhecida; evidentemente, com uma leitura crítica, pois, uma antropologia que busca acumular melhor o conhecimento e afinar suas teorias, metodologias e etnografias, deve prestar atenção e revisitar os escritos e as ideias anteriores. O valor do texto reside, assim, no seu testemunho histórico e, talvez, ainda possa oferecer uma pequena contribuição para a etnologia contemporânea dos povos indígenas no Nordeste brasileiro das Terras Baixas da América do Sul (veja-se Carvalho e Reesink n.p.).

Assinalo, ainda, que a realidade que o artigo se propôs a etnografar - o autoconvencimento e a autoidentificação como índio, num recorte sincrônico - não é mais a mesma em Massacará, no sentido de que, atualmente, há uma postura muito mais afirmativa de indianidade. Aliás, em consonância com essa tendência histórica geral, no Nordeste inteiro percebe-se um aspecto primacial concomitante: o incremento do alterconvencimento (a afirmação de indianidade perante os brancos/posseiros), alimentando a ação coletiva pelos índios. Consequentemente, o que está descrito nesse artigo revela um momento histórico anterior ao contemporâneo, ao mesmo tempo em que já aponta para alguns desdobramentos futuros, o que ressalta o seu valor histórico. 
"A raça é ruim, a raça é fraca"

Português casado com uma índia e que afirmava desejar que seus filhos fossem índios.

\section{A identidade étnica: terminologia}

Um dos pontos mais complexos e intrigantes em Massacará é exatamente a questão de quem, de fato, seja índio, numa população em que se opõem caboclos e portugueses. ${ }^{2}$ Em primeiro lugar, quando se observa a população sem saber quem é considerado como tal, é muito difícil ou até impossível a classificação das pessoas por meio de traços fenotípicos. Em termos genotípicos, os caboclos são de descendência indígena misturados com brancos e negros, fazendo com que se apresente um espectro de aparências que vai de índio nas direções de branco e negro. Isso não significa que sumiram as noções negativas contra os índios. Pelo contrário, pode-se escutar, por exemplo, que sempre se conhece um caboclo pelo seu gênio, que é bruto, ou seja, não-civilizado. De modo similar, existem noções negativas contra pessoa negras, escutando-se, por exemplo, uma frase como eu não gosto de negro, mesmo se uma expressão dessa não costuma ser feita na frente de uma pessoa mais escura. Uma vez uma pessoa externou essa frase na frente de todo mundo e as outras pessoas pareciam um pouco incomodadas pela sua franqueza. Outra vez isso ocorreu sem que o enunciador se desse conta da presença de uma pessoa mais escura, sentindo-se obviamente incomodada pela possibilidade de que a outra pessoa pudesse lhe ter ouvido. Essas noções sobre negros são compartilhados por brancos e índios. No que tange aos índios, a sua expressão parece ser um pouco mais livre e menos inibida. Dada à miscigenação, pode-se ouvir a afirmação aqui não tem índio, só caboclo misturado com negro. A implicação sendo, é claro, de que de duas coisas desvalorizadas somente pode resultar algo pior.

$\mathrm{O}$ aspecto mencionado até aqui se refere ao fundo racial. As noções devem ser aprofundadas um pouco mais para revelar umas con- 
tradições curiosas. Há dois elementos para definir o indio, um sendo a herança racial, a outra sendo a herança cultural. Naturalmente, na mente popular essas duas dimensões se interrelacionam numa relação causal. A citação do português na epígrafe desse artigo se refere em primeiro lugar ao lado racial, mas implicitamente se estende a outras qualidades. $O$ ponto interessante na definição do indio mesmo, ou indio legítimo, é que contem os dois elementos: às vezes é utilizado para se referir ao racialmente puro, às vezes ao culturalmente diferente, ou aos dois elementos simultaneamente. No que toca à pureza racial, essa foi perdida e, ao invés de diminuir o preconceito, a noção de caboclo permanece negativada e sujeita ao preconceito, mesmo que sua aparência possa ser mais branca do que um regional não-índio. Um índio puro ainda pode merecer algum respeito por ser puro contra o seu descendente não legítimo que, uma vez misturado com brancos e, nesse sentido, na realidade parcialmente da raça branca, não é mais legítimo. ${ }^{3}$ Nota-se a contradição irônica de que estar mais próximo (do branco), racialmente, funciona negativamente exatamente por não ser mais distante. Perde-se pelas duas vias, tanto faz ir por um lado como por outro.

Quase o mesmo argumento é válido para o outro elemento. Numa oportunidade conversei com um jovem português, com o seguinte diálogo aproximado:

Eles não são índios.

Porque não?

Porque não são.

Mas tem que ter uma razão porque não são.

Sei lá, não são.

Mas por quê?

Eu vou lhe dar uma razão. Eles se vestem como índios?

Em outras palavras, não eram índios porque não cumpriam o critério de serem culturalmente diferente. Logicamente perguntei se havia diferenças entre caboclos e portugueses, como é expressa, normalmente, a oposição na terminologia. Depois de alguma hesitação, os três 
portugueses presentes naquele momento admitiram de que, até onde sabiam, não havia diferenças.

Os caboclos velhos, os ancestrais indígenas, por outro lado, são legítimos, e, até certo ponto, admirados por seu saber do sobrenatural. Porém, esse saber de herança cultural não tem sido transmitido para as gerações atuais. Como sabemos, essas gerações foram objetos de uma perseguição feroz, talvez elas tenham adotado uma estratégia consciente de não transmitir seus saberes, almejando uma aculturação que pudesse diminuir as atitudes persecutórias a que estavam submetidas. De fato, a discriminação diminuiu bastante, mas a sujeição conceitual não se modificou. Mais uma vez, por uma contradição que pode parecer irônica, se acusa os descendentes do fato de que eles não conhecerem mais os costumes dos seus ancestrais. Desse modo, os índios sempre estão numa posição de perdedor: se são culturalmente diferentes, são selvagens; se não diferem culturalmente, então são caboclos e inferiores exatamente porque não são mais indígenas. A questão que surge, portanto, é se não são mais considerados índios, porque que são caboclos? O termo caboclo implica, dessa maneira, numa conotação denigrante, devido à mistura de raça e da aculturação. Às vezes o termo pode ser usado para denotar pureza, mas aí sempre é adjetivado com mesmo, ou legitimo. ${ }^{4}$

Os índios estão perfeitamente conscientes dessa semântica e, às vezes, parecem hesitar para afirmar que são índios, já que não se sentem legítimos. Isso é uma indicação de que as ideias negativas dos portugueses em parte têm sido assimiladas pelos caboclos. É difícil averiguar até que ponto isso seja verdade, mas o que se diz é que os portugueses desmoralizam os caboclos e isso parece indicar que são afetados por esses significados e as observações discriminatórias que se ouve às vezes. Parece que é dado algum crédito a essa posição ideologicamente inferior, e, ainda mais, não se contesta nesse nível. Por exemplo, nunca ouvi uma opinião que revertia a posição inferior dos índios, no sentido de que eles são superiores, ou, pelo menos, iguais. No entanto, isso não significa que os caboclos agem como se 
fossem inferiores, pelo contrário, eles agem como iguais e são tratados como pessoas individuais, de acordo com seu status de homem, pai de família, idade. Na realidade, dificilmente percebi diferenças em comportamento na vida cotidiana. Advirto, todavia, que podem haver pequenas diferenças se houvesse uma pesquisa mais aprofunda nesse sentido. Note-se, diga-se de passagem, que na vida cotidiana não parecem existir sinais ou símbolos que diferenciam os dois grupos. Mais uma vez, ainda é possível que seja devido a falta de uma busca mais detalhada. De todo modo, a contradição maior talvez seja entre a ideologia e a vida cotidiana. Os caboclos são simbolicamente postos como inferiores, mas na realidade do comportamento factual isso quase não aparece. ${ }^{5}$ Os índios sabem perfeitamente de sua posição subordinada e às vezes se comenta que uma nação não devia brigar com outra. Implicada nessa afirmação está a evidência de que, de todo modo, os portugueses sempre estão numa posição de maior força. A expressão desvela que a subordinação é relativamente aceita. Poucos caboclos se mostram dispostos a iniciar um enfrentamento coletivo. A grande maioria aparentemente pensa que, dado as condições atuais, melhor uma acomodação do que um conflito, já que, na sua avaliação, tudo conspira para que percam. ${ }^{6}$

O termo nação se refere aos respectivos grupos de caboclos e portugueses, indicando uma coletividade. Outro termo em circulação entre os índios, para se referir a si mesmo, consiste de o velho tronco. Eles não se chamam de Kaimbé, termo que somente surgiu espontaneamente uma vez na frase de um português casado com uma índia: dizem que os caboclos são descendentes da tribo Kaimbé. Os Kaimbé se tornaram caboclos de Massacará. Da mesma forma, o modo usual de falar dos Kiriri de Mirandela é o de chama-los de caboclo de Mirandela. A oposição normalmente não se traduz em termos de civilizado-índio, onde o termo índio tende a ter uma semântica de um ideal fenotípico de ser puro. Talvez a tendência da sociedade nacional, de ignorar as diferenças étnicas entre os indios, contribuiu para essa nominação. A sua qualidade principal, nesse sentido da visão portuguesa, concernente 
ao ser caboclo, pesa menos do que seria a sua origem (de Massacará ou de Mirandela), embora os índios Kiriri que moram em Massacará continuem ser classificados como caboclo de Mirandela. Ambos, como visto, parecem ser grupos também racialmente discriminados. A identificação com um grupo étnico específico tem sido substituída por um termo genérico, caboclo, diferenciando-se depois em termos de lugar de origem. ${ }^{7}$

É bastante frouxa a organização interna do grupo, sendo que pouco se nota iniciativas coletivas por parte dos próprios índios. Talvez a pressão externa também não seja forte o suficiente para que tomem mais iniciativas coletivas. Os grupos domésticos se consideram como independentes, iguais e suas inter-relações, em princípio, como simétricas. Esse modelo camponês regional não facilita uma organização coletiva mais efetiva. Além disso, os grupos étnicos não se separam em espaços rigidamente diferentes. Às vezes portugueses e caboclos moram dispersos, próximos uns dos outros. Apesar de que é difícil estabelecer como isso acontece na realidade concreta, geralmente se assevera que é importante ser um bom vizinho. Além de certa vizinhança geográfica, a miscigenação racial que prolifera cria importantes laços de sangue. A maioria, ou, talvez, até todos, dos índios possuem parentes do grupo étnico oposto. Portanto, muitos portugueses, pelo outro lado, também mantém laços de parentesco com índios, apesar de que isso não significa que essas pessoas não partilhem das ideias negativas sobre caboclos. Verbalmente se escuta dizer que é mais importante ser parente do que seu status étnico. Amizades também não se limitam ao grupo a qual a pessoa pertence. A participação em atividades coletivas pode juntar índios e não-índios, não obstante, há uma tendência de que a composição dependa da identidade da pessoa responsável, ou seja, aparentemente a presença do seu grupo tende a ser mais forte. ${ }^{8}$ Em situações concretas, essas condições expõem uma pequena distância social entre os dois grupos opostos. O índio está sendo, assim, apreendido como um indivíduo e não como uma categoria. A questão que surge é em que medida sua identidade étnica se sobrepõe às ou- 
tras características de que é portador e que são utilizadas para estimar o tratamento correto a que faz jus.

Em suma, a discriminação parece ser mais latente do que visível à primeira vista. Geralmente, em situações de contato pessoal direto, evita-se declarações com um conteúdo discriminatório. Somente em algumas ocasiões emergem essa observações, tal como nos jogos e treinos no campo de futebol, quando todos os meninos que querem entrar em campo podem participar, inclusive vários jovens caboclos. Quando um caboclo joga mal, é possível ouvir comentários nesse teor, tal como: caboclo danado, caboclo não presta. Por outro lado, o critério para jogar no time de Massacará, quando joga contra times de outras localidades rivais na região, é habilidade e, por isso, há caboclos que jogam por Massacará. ${ }^{9}$ No caso de algum caboclo que, quando bêbado, não respeita outras pessoas, a reação pode chegar a uma brincadeira carregada de certa violência. Nesse caso, não conheço o suficiente de casos semelhantes para garantir que esse comportamento resulte do fato de ser caboclo, ou se essa condição agrave a reação do desrespeitado comparado com bêbados portugueses na situação similar. O que precisa ser feito ainda, portanto, é averiguar com mais exatidão o peso da condição de caboclo em comparação com as outras classificações da pessoa.

\section{Identificação étnica}

Dada a discussão anterior, não surpreenderá que a aplicação do termo caboclo às vezes cause certa confusão. As características corporais externas não servem para distingui-los, já que há um índio com olhos azuis, e não-índio com 'cara de índio'. O critério principal para a determinação do status étnico, da transmissão da denominação caboclo, é por meio da herança direta dos pais - mãe, pai ou os dois. Não em todos os casos, por outro lado, porque existe a possibilidade de se tornar caboclo por meio de um casamento, um status adquirido. Um(a) português(a) que casa com um(a) caboclo(a) pode acompanhar o(a) parceiro(a). Ou seja, a pessoa opta por se afiliar ao grupo do côn- 
juge. Para um caso desses, três alternativas se oferecem: não acompanhar e continuar português; acompanhar e permanecer português; acompanhar e, ao longo do tempo, assumir a identidade de caboclo. Evidentemente, a última possibilidade cria certa confusão porque a pessoa pode se considerar indígena mas a mudança pública de status somente ocorrerá com o tempo. Essa mudança depende de vários fatores, tais como a sua disposição e a relevância de suas relações com os afins. Talvez haja uma tendência a que portugueses de Massacará não mudem de identidade étnica. É difícil saber com certeza. Para averiguar melhor necessitar-se-ia de uma pesquisa bem mais aprofundada, que levantasse todas as histórias de vida das pessoas, ora consideradas indígenas. A condição de acompanhar se mostra importante para o status futuro dos filhos. Idealmente, um dos pais acompanha o outro e tal fato determinaria o status da filiação dos descendentes. Se o pai português acompanha, o filho será índio, senão será português. Veja uma maneira de representar isso no diagrama abaixo.

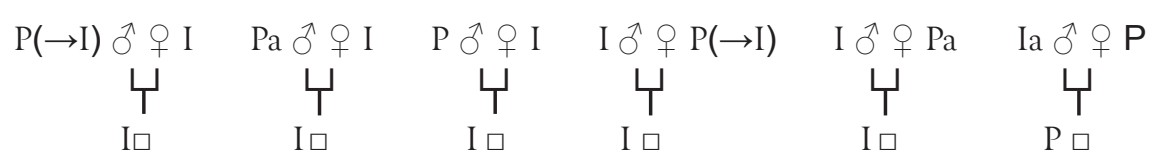

P para português.

I para índio.

$\mathrm{P}(\rightarrow \mathrm{I})$ para português que se torna $\mathrm{I}$.

Pa para português que acompanha o cônjuge.

Ia para índio que acompanha o cônjuge.

$\square$ para filho/filha. Igual para descendentes masculinos e femininos.

Veja-se que um português pode se tornar índio, mas que o inverso não pode acontecer. Desse modo é possível se pronunciar membro do grupo inferior, mas não é possível deixar de ser caboclo. Esse processo é raro, a herança racial predomina. A conjugação do princípio do status prescrito e do adquirido complica o princípio da transmissão. 
A aceitação das regras culturais não-indígenas de herança se mostra em alguns pontos tal como uma certa bilateralidade: na adoção de sobrenomes e na divisão igual de bens quando os pais falecem. Todo filho herda dos dois pais. Dessa maneira os filhos constituem uma síntese dialética das categorias opostas de índio e português. Todavia, não há uma categoria especial inventada para classificar o amálgama, tal como acontece no caso de branco e negro quando se produz uma categoria intermediária, mulato. A solução para esse problema de definição será quando um dos pais está acompanhando o outro, ou quando um dos pais gradativamente muda de status de português para índio. Obviamente, e por isso não presentes no quadro, filhos de pais que são ambos índios (ou portugueses) não tem qualquer escolha. Quando um dos pais acompanha, também parece que não tem escolha. Por outro lado, o problema está no grau de acompanhar. Se a vontade dos pais coincide na escolha de um lado, muito provavelmente o filho seguirá o desejo. Assim, num determinado caso, suspeito, com boas razões, que um caboclo se casou uma portuguesa para que seus filhos fossem daquele lado. Em alguns casos, as preferências não se expressam tão claramente e o status dos filhos permanece um tanto obscuro. Aparentemente, quando não se demonstra muita paixão, especialmente por parte de pai/mãe português, os filhos terminam por serem indígenas. Não obstante, também é possível para uma criança de status indefinido com pais menos ardorosos, de se afirmar como português quando chega por volta de 16 a 18 anos.

Uma vez, andando na trilha arenosa para chegar numa casa, perguntei a um adolescente morador nessa casa como ele se definia. Ele respondeu: eu não sei o que sou. Esclareci que o pai dele me informou que ele e seus irmãos mais velhos eram portugueses, exceto uma irmã casada com um caboclo, enquanto os mais novos pertenceriam ao grupo caboclo. Diante disso ele insistiu, eu não sei o que sou. Sua indefinição reflete, em primeira instância, que a potencial solução mencionada continua a representar uma clara área de incerteza. Nota-se que a vontade do pai é importante, mas que mesmo assim, o filho resiste 
e demonstra vontade própria. Ao que tudo indica, se não houver uma decisão de querer ser português e expressar claramente essa vontade, uma pessoa de dupla descendência tende a ser caboclo. Fato que, em si mesmo, ilustra o preconceito. Creio que a decisão depende de fatores psicológicos, tal como na medida em que a pessoa crê no preconceito, e de fatores sociais, tal como se a sua rede de relações pessoais cobre mais um ou outro grupo. Resumindo:

1. Quando os pais são caboclos, os filhos não têm escolha. Qualquer um que queira mudar de lado não poderá fazer isso em Massacará, somente em outros lugares onde não será conhecido. Existe, vale observar, uma espécie de núcleo duro de caboclos que não escondem sua etnicidade e não tem medo de assumir a mesma. Para outros, constitui um estigma que gostariam de abolir, se fosse possível. Outros ainda parecem ser mais indiferentes, não atribuindo grande valor ao ser ou não ser índio. As proporções dessas diversas posições são difíceis de serem aferidas com maior precisão.

2. Filhos de casamentos mistos, com dois pais considerados diferentes, pertencendo ou a um ou outro grupo. Aqui vale acrescentar que a opcionalidade cria conjuntos de siblings que pertencem aos dois grupos. Tem um caso conhecido em que um irmão se inclui nos índios, e outro irmão entre os não-índios (também viveu muito tempo fora da área indígena). Mesmo assim, uma pessoa nessa situação pode comentar negativamente sobre caboclos. Nesse sentido, os casos de pessoas indígenas, que casam fora do grupo, resultam em perdas numéricas.

3. Pais portugueses que acompanham o cônjuge ao ponto de pretender mudar de grupo, o que causa uma impossibilidade de escolha ou, certamente, uma dificuldade de escolher ser português.

4. Pais (caboclos ou portugueses) que acompanham o cônjuge, mas não mudam de grupo, indicam o grupo aos filhos, mas dei- 
xam alguma margem de escolha (creio ser mais difícil querer ser português).

5. Pais que nem acompanham nem mudam de grupo, quando deve ser mais fácil para o filho seguir o grupo desejável. A diferença de quem acompanha para quem não acompanha é gradual, mas é relevante por causa da limitação maior ou menor dos filhos.

6. Portugueses casados com portugueses, para quem, normalmente, essa situação de potencial indecisão dos filhos não ocorre.

Certa confusão e contradição, portanto, reina e possibilidades para a manipulação se oferecem. Vejamos a definição de índio, segundo o Estatuto do Índio (a lei 6001): "índio ou silvícola é todo indivíduo de origem e ascendência pré-colombiana que se identifica e é identificado como pertencente a um grupo étnico, cujas características culturais o distinguem da sociedade nacional". Note-se três elementos distintivos: ascendência, auto-identificação e identificação pelos outros. A acreditar no exemplo citado, a definição exclui os índios de Massacará por falta de cultura diferenciadora. Outros se excluem por não serem de descendência indígena. Para a auto-identificação, dois fatores são os mais relevantes: a presença de preconceito e a instalação de um subposto indígena da Funai. A Funai está presente na pessoa de um auxiliar administrativo. Para este, as pessoas que assumiram ser índio não contam como tal. Por outro lado, ele inclui toda a geração mais nova de casamentos mistos na população indígena e com os direitos concomitantes (mesmo se considerados não-indígenas). Uma aplicação restrita da definição legal não resolve os problemas dessa situação. A presença do subposto, com as suas vantagens (mesmo que bem limitadas), contra as desvantagens de sofrer preconceito, pesam na escolha dos pais e da pessoa em posição mista. Compreende-se, assim, algo a respeito de certas duvidas e oscilações.

Para muita gente, ou todos, o que importa mesmo em relação ao subposto e sua assistência é estar na lista ou não estar na lista. Desde o início das atividades estatais muita gente se alistou, mesmo 
não sendo indígena. Certos servidores, ao fazer um censo, ajudaram nisso. ${ }^{10} \mathrm{Em}$ 1959, uma professora do SPI conduziu um censo para registrar todas as crianças em idade escolar. $\mathrm{O}$ inspetor da época, Geraldo Vieira de Mello, percebeu o perigo. A professora, segundo ele, tornou-se neurótica:

"Comprava ainda o estado de sanidade mental alterado da professora (...), é que tenha tomado o expediente de levantar por conta própria, um recenseamento de índios, incluindo e registrando como índios, todos os fazendeiros e até os brancos da região. De futuro, os invasores de terra se julgarão índios registrados e cohonestarão certamente todas as injustiças. Acresce, ainda, a mesma se arroga o título de resolver casos em Massacará e tenho contornado sérias dificuldades" (Doc. consultado no Posto Indígena de Mirandela).

Mesmo hoje se escuta o comentário ele é enlistado no posto, como se desse algum direito, quando é claro que a pessoa não é índia. Os caboclos também atribuem bastante valor à lista. Quando um índio se zanga com o auxiliar, por algum serviço que o chefe pediu, mas considera não razoável ou por ter um pedido dele não atendido pelo mesmo funcionário, ele pode responder tira meu nome da lista. Acontece que o auxiliar, conhecido como chefe, recebe semelhante demanda mesmo que sem uma maior razão aparente, quase como se fosse o suficiente para deixar de ser índio.

Podemos resumir as combinações possíveis usando a definição de índio e ver o conjunto:

$\begin{array}{llll}\text { Combinação } & \text { Descendência } & \text { Definição por Outro } & \text { Autodefinição } \\ \text { a } & \text { indio } & \text { índio } & \text { índio } \\ \text { b } & \text { indio } & \text { índio } & \text { não-índio } \\ \text { c } & \text { indio } & \text { não-índio } & \text { indio } \\ \text { d } & \text { índio } & \text { não-́ndio } & \text { não-índio } \\ \text { e } & \text { não-índio } & \text { indio } & \text { indio } \\ \text { f } & \text { não-índio } & \text { índio } & \text { não-índio } \\ \text { g } & \text { não-índio } & \text { não-índio } & \text { indio } \\ \text { h } & \text { não-índio } & \text { não-índio } & \text { não-índio }\end{array}$


Combinação a e e $\underline{h}$ não implicam em dificuldades. Se for filho de casamento misto, a pessoa opta para $\underline{a}$ ou $\underline{h}$. Acontece que uma pessoa $\underline{\mathrm{d}}$, que pretende ser não-índio pode, como visto, ser contado como enlistado no subposto, visando as vantagens oferecidas, se autodefinindo na oportunidade como c. A manipulação de autodefinição parece ser o mais fácil. Para certa ocasião, por exemplo, para pessoas de fora, uma pessoa indigena, mas com um pai não-índio, pode se apresentar como português, usando as combinações possíveis para sua situação (b). Várias combinações aplicadas já foram vistas, tal como e (mudou de grupo), mas a mesma pessoa poderia se apresentar como sua identidade de origem, se conveniente (seria $\underline{f}$ nesse propósito). Uma pessoa casada com parceiro indígena não necessita realmente modificar seu status, porque o posto confere direito de assistência ao cônjuge. No entanto, socialmente, pode acompanhar ou almejar mudar de grupo, com a ambiguidade inerente a essa situação. $O$ quadro permite pensar as permutações possíveis relacionadas às situações em que ocorrem. Desse modo, teríamos casos como:

$\underline{\mathrm{a}} \leftrightarrow$ (se apresenta) $\underline{\mathrm{d}} \approx($ seria) $\underline{\mathrm{b}} ; \underline{\mathrm{d}} \leftrightarrow \underline{\mathrm{a}} \approx \underline{\mathrm{c}} ; \underline{\mathrm{e}} \leftrightarrow \underline{\mathrm{h}} \approx \underline{\mathrm{f}} ; \underline{\mathrm{h}} \leftrightarrow \underline{\mathrm{e}} \approx \mathrm{g} ; \underline{\mathrm{h}} \leftrightarrow \underline{\mathrm{d}} \approx \underline{\mathrm{h}}$.

O problema, nessa maneira de apresentação, é que os três elementos em jogo contém suas ambiguidades. ${ }^{11}$ Descendência aqui se define no sentido do status dos pais. No caso de $\underline{h}$, com todos os elementos não-índios, por exemplo, ainda aparecem casos em que as pessoas possuem ancestrais mais distantes e reclamam direitos em função disso. Definindo, então, a descendência mais amplamente. A autodefinição, em princípio, clarifica se pertence a um lado ou ao outro. Mas, na realidade, as pessoas às vezes fogem de definir isto claramente. Dois civilizados (termo mais usado pelo auxiliar do que por eles mesmos e pelos índios), casados com índias do outro grupo e que acompanham para se identificar com as parceiras, não queriam admitir ser português, mas também não se sentiram confortáveis em se definir índio: me disseram ser embrulhados. ${ }^{12}$ Para fugir da pergunta, ou porque 
parece que não havia aceitação pública geral de suas pretensões, se apresentaram com uma espécie de categoria intermediária. Alguns os aceitam, outros não concordam. Nesses episódios, no caso da aparente indecisão, vale alertar que as pessoas, possivelmente, confundiramme com um funcionário da Funai: corriam algumas suposições sobre minha presença e a razão de estar ali, e que, até onde sei, nem sempre se dissiparam.

A opinião dos outros, a definição pelas outros moradores talvez seja o critério mais difícil. A opinião dos outros, como acabamos de ver, se revelou bastante difusa e depende da interação social em curso. Um processo de se tornar outro automaticamente cria uma fase confusa, se é que tenha um fim unânime. Uma pessoa de descendência mista sempre terá, de certa forma, uma zona de ambiguidade a explorar, tal qual seus pais quando ela é de menor. Em um conflito, uma das pessoas pode sempre lembrar o fato da origem mista do oponente, como uma categoria de acusação. Nesse sentido, de maneira latente, o sangue do caboclo nunca se repudia por completo. Numa dada situação, a maioria dos presentes pode opinar de uma maneira e uma minoria de outra forma. O critério de definição pelos outros não se resolve ao simplesmente pedir a uma pessoa para atribuir uma identificação a todas as pessoas conhecidas. Além disso, uma pessoa conhecerá melhor certas pessoas do que outras em Massacará e, consequentemente, pessoas diferentes classificam uma mesma pessoa em grupos opostos, o que acontece mesmo para pessoas portuguesas já adultas. Talvez, por hipótese, quanto menos contatos pessoais relevantes entre as pessoas, menos provável de que se saberá da sua identidade. Mas, mesmo para uma pessoa menos conhecida, qualquer um fará uma estimativa de sua identidade numa interação cotidiana, para saber como agir. Parece que esse conjunto de elementos aponta para que a identidade de caboclo nem sempre pese muito na composição da identidade social e, talvez, tenha decrescido em sua relevância no tempo. Às vezes as pessoas não sabem direito das regras que se aplicam. Um jovem português pensava que o princípio da transmissão fosse patrilinear, e que 
a mulher sempre acompanhava o marido. Somente depois da minha chegada ele percebeu que se enganara. Outro pensava que somente não-índios de fora de Massacará pudessem mudar de status. Algo, aliás, que certamente me parece uma tendência, pela fixação cotidiana anterior da identidade, mas sobre o que não tenho certeza. Não sei em que medida se estende uma certa confusão sobre identidades e regras de atribuição.

Quando fiz um censo, por outro lado, em geral a auto-identificação e a identificação por outros coincidia, mas em alguns casos as opiniões diferiam e, para fins do censo, segui a maioria. A opinião pública se relaciona com o comportamento social. Num caso notório, as opiniões se dividiam em linhas étnicas. A opinião geral condena uma determinada família como antisocial. Com suas ações eles vitimaram alguns caboclos, violando uma certa norma, não muito operativa, de que não se abre conflitos com outros índios. Eles se achavam incluídos no grupo caboclo, continuam a se afirmar como tal, e os portugueses confirmam essa identidade. Contudo, o grupo indígena agora nega sua inclusão, implicando numa expulsão moral do seu grupo, mesmo que não se tenha cortado todas as relações. Não sei se essas relações diminuíram em comparação ao tempo anterior. Um grupo estigmatizado normalmente se mostra sensível ao embaraço causado por seus membros, que atinge a todos. Nesse caso, alguns comentavam que não pertenciam ao velho tronco, e com alguma razão, já que o chefe da família, viúvo, era casado com uma não-índia e ele mesmo já era de descendência mista. Quando um membro deste grupo quis abrir uma roça numa terra num certo terreno, querendo cerca-lo, os moradores se uniram em protestar e impedir que ele realizasse seu intuito, já autorizado pelo auxiliar da Funai. Já havia alguns moradores com alguma pretensão sobre a mesma área, mas, provavelmente, a reação não alcançaria tal proporção e nem se oporia tanto ao auxiliar se aquele não pertencesse a tal grupo. Fora esse caso especial, por fim, vale lembrar que realmente os próprios índios divergem sobre os limites do seu grupo. Por exemplo, um homem, 
que durante um curto tempo assumiu como cacique, externava sua vontade de impor mais limitações e de se concentrar nas pessoas mais firmemente relacionadas ao velho tronco, ou seja, com laços de família mais densas, mais fortes. Outras pessoas, que me pareciam ser a maioria, enfatizavam mais o significado do sangue como uma justificativa para ser mais inclusivo.

Concluíndo ao texto, podemos dizer que, nos limites étnicos, e sobre os limites étnicos, reinam certas divergências, mas, ao todo, se demonstra o compartilhamento da relevância do critério do sangue (raça), e da atribuição social da identidade pelos dois lados em oposição. ${ }^{13}$

\section{Notas}

1 Com bem poucas mudanças de estilo ou de esclarecimento atual, o texto almeja ser ao máximo fiel aos textos antigos. $\mathrm{O}$ fato de ter sido escrito em inglês, outra língua estrangeira para mim, se reflete numa prosa mais simples e menos refinada. Além das notas originais, inseriram-se aqui notas explicativas que objetivam esclarecer alguns pontos, seja em relação ao texto em si, seja em referência à literatura da atualidade.

2 [Nota explicativa] Preciso esclarecer que o título da etnografia também se refere a essa oposição: os olhos miúdos são os caboclos, os olhos graúdos sendo os portugueses. Um índio Kiriri que morava em Massacará me explicou que a sua mãe usava essa expressão para justificar que ela não ensinava mais certos conhecimentos indígenas para os filhos (no caso, achar água numa caatinga seca, aparentemente sem água): porque os olhos miúdos ainda iam sofrer muito dos olhos graúdos. Note-se que: primeiro, a distinção se faz por característica física externa no rosto (a parte mais significativa para interação social); segundo, se interrompe a transmissão de conhecimento indígena na esperança de ajudar as gerações mais novas (a declaração aconteceu no pior período na historia Kiriri, depois da calamidade de Canudos, primeira parte do século XX); terceiro, se utiliza também a oposição miúdo e graúdo, mas metaforicamente para denotar diferença em poder econômico e político, tal como gente graúda para referir-se aos poderosos.

3 [Nota explicativa] Vale lembrar que, ao usar aspas no texto original, eu quero deixar claro de que o termo raça se refere a uma categoria nativa, não uma categoria com qualquer uso científico, para o qual raça não deve existir como conceito analítico-teórico. $\mathrm{Na}$ epígrafe deste texto, por exemplo, a pessoa citada se refere a um caboclo que não sabe negociar, atribuindo esse defeito a uma falta de capacidade inata.

4 [Nota explicativa] Esclarecendo melhor, aqui eu apontava para o fato de que, com esse uso, o termo caboclo praticamente se transforma em um sinônimo de índio. 
Tal como, aliás, na expressão caboclos velhos. Faltou esclarecer melhor aqui que, dessa maneira, alguém fenotipicamente indígena pode não ser considerado caboclo, e alguém fenotipicamente pouco índio pode ser caboclo. Como, de fato, verifiquei na época. Merece menção, ainda, que o leitor talvez fique com a impressão, pela redação do texto, de que não há caboclos que se auto-identificam como indio com convicção. Menciono mais adiante, porém, como algumas pessoas expresssam com firme autoconvencimento de si o fato de serem indios, e se identificam como tal perante os não-índios, na tentativa do alterconvencimento da justiça de sua auto-identificação.

5 Esse ponto merece, então, pesquisa posterior. Pesquisar melhor, constatar e revelar, quando a identidade de caboclo se mostra decisiva para um tratamento discriminatório, iria diminuir essa contradição.

6 [Nota explicativa] Avaliação resultante da experiência histórica de perdas e que me parecia bastante realista. A proteção do Serviço de Proteção ao Índio se revelou muito pouco eficaz. Embora sua presença inibiu um esbulho maior, não se modificou a desigualdade de acesso à terra. Isso também influiu na fraca mobilização coletiva mencionada adiante.

7 [Nota explicativa] Explicitando um pouco, lugar de origem denota o lugar de nascimento. Para os índios, as pessoas e pequenos grupos que fugiram da violência ou saíram de Massacará, para tentar viver em outro lugar, e os seus filhos, permanecem ligados à noção de caboclos de Massacará. Há pequenos grupos assim na região, em Muriti, As Tocas (Várzea do Burro) e Boqueirão (visitei os primeiros dois locais para ter um pouco de noção sobre essas migrações).

8 Aqui, infelizmente, preciso confiar somente em respostas verbais. Por exemplo, para a composição de um batalhão (nome local para um mutirão; os poucos que assisti tendiam a ser bastante limitados aos índios). O período do ano da realização da pesquisa não coincidia com essa atividade, além de que se terminava de sair de uma seca. Em outros casos, me parece que a realidade confirma a presença de uma quantidade significativa de participação em atividades uns dos outros, além de amizades.

9 Por outro lado, quando um índio joga bem, este ganha admiração em função de sua habilidade. Bons jogadores adquirem certa fama na região. $\mathrm{O}$ critério para poder ser selecionado é moradia no local, o que faz com que um estudante de antropologia temporariamente morando em Massacará pode ser chamado para jogar no time (na verdade, chamado pelo dono do time, aquele que possui as camisas e que organiza os jogos). A minha inclusão certamente ajudou a me fazer mais conhecido em Massacará (e redondezas), e, creio, ajuidou a ganhar certa aceitação entre todos os moradores.

10 Essa atitude de se estar na lista, se correlaciona com a concepção de que o dinheiro público, de qualquer nível, deve servir para todos. Tudo é um dinheiro só, e, mais, é de todos nós. Dessa forma, os não-índios se sentem discriminados pela atenção diferenciada da Funai para com os índios. O dinheiro publico é escasso, todos merecem e muitos são pobres, ou seja, como se pode 'privilegiar pessoas inferiores?'.

11 [Nota explicativa] Notemos que haveria, portanto, outras formas de apresentar a combinação dos três critérios. Podemos fazer um fluxograma de decisões partindo de cada um: por exemplo, a pessoa se auto-identifica como índio, é alteridentificada como tal no seu lugar de origem, mas não se apresenta com tal 
quando migra para São Paulo (I-I-P, quando em Massacará seria I-I-I). Da mesma maneira, todo fluxograma termina por obter 8 combinações; a escolha para um que sai de um dos critérios, auto-alter-origem, se justificaria em termos de qual melhor se adequaria à situação etnográfica e para explorar mais sistematicamente os contextos em que se realizam. Aqui segui a definição que, como se sabe, se tomou emprestada de Darcy Ribeiro, em que se sai de uma suposta determinação prévia. Hoje se dá muito valor à auto-identificação, com justiça, porém, existe um critério de descendência que, no senso comum, determina a pessoa, mesmo que, como está no texto mais adiante, o mesmo se revela mais complexo do que a lei pressupõe. Nesse sentido, uma modelação etnográfica deve levar em conta esse vetor concebido como independente da pessoa. Iniciar um mapeamento dessa complexidade é o mérito do presente texto.

12 [Nota explicativa] $O$ texto especifica esse termo, o que não deixa de ser possível. Por outro lado, em outros lugares, se encontra em especial o termo braiado como sendo o termo comum para essa situação, e, então, posso ter me enganado. No entanto, uma vez vi uma explicação sertaneja que derivava braiado exatamente de embaralhado. Convém, por outro lado, não exagerar demais na importância do fenômeno da mudança étnica, já que, na minha avaliação, contei só um homem e três mulheres como casos confirmados (enquanto haviam mais 22 homens e 7 mulheres na mesma condição conjugal). Vale acrescentar que estimei que, com a ressalva de todas as dificuldades já mencionadas, nas gerações mais novas um quarto deles terminaria como não-índio, e que por volta de três quartos optariam pelo lado indígena. $\mathrm{Na}$ atualidade, esta questão poderia ser revista, para saber em que medida a estimativa se concretizou ou não.

13 [Nota explicativa] As últimas frases foram acrescidas na edição do texto. Porém, creio que se assemelham ao espírito em que o texto tinha sido escrito. $\mathrm{Na}$ turalmente, hoje reveria o texto à luz dos textos posteriores, em especial os que se inspiraram no presente texto: 'uma questão de sangue' (1999) - que trata do sangue como operador de parentesco que vincula a pessoa aos ancestrais indígenas; e 'alteridades substanciais' (2011), em que se investiga o sangue como uma substância que encerra um vetor sociomoral - força herdada que influi na concepção da pessoa no Brasil.

\section{Referências}

BANDEIRA, Maria de Lourdes. 1972. Os Kariris de Mirandela: Um grupo indígena integrado. Estudos Baianos. Salvador: UFBA/Secretaria de Educação e Cultura do Estado da Bahia.

CARVALHO, Ma. Rosário de \& REESINK, Edwin B. No prelo, "Uma Etnologia no Nordeste Brasileiro: balanço parcial sobre Territorialidades e Identificações," Revista Brasileira de Informação Bibliográfica em Ciências Sociais, no prelo. 
REESINK, Edwin B. 1999. "Uma Questão de Sangue". In BACELAR, J. \& CAROSO, C. (eds.): Brasil: Um país de negros?, pp. 187-206. Rio de Janeiro: Pallas/CEAO.

REESINK, Edwin B. 2011. "Alteridades Substanciais: Apontamentos diversos sobre índios e negros." In CARVALHO, M., REESINK, E. \& CAVIGNAC, J. (eds.): Negros no Mundo dos Índios: Imagens, reflexos, alteridades, pp. 245-288. Natal: EDUFRN.

\begin{abstract}
In this paper I try to record and analyse the terminology, identifications and the relations between caboclos and Portuguese, as the Indians and civilized of the two sides in opposition are usually denominated. The monograph is an ethnographical record of 1976-1977 of the Kaimbé Indian people who live in the Northwestern sertão of Bahia, in Massacará (municipality of Euclides da Cunha). The basic question concerns the identification of oneself, the identification by others and the criteria of ethnic belonging. As there have been and still are a considerable amount of mixed marriages, I discuss how the children of mixed descent dispose of a certain latitude in order to decide to which side they want to belong.
\end{abstract}

Keywords: Indians; Kaimbé; Ideology Ethnic; Mixture; Auto-identification; Alteridentification.

Recebido em outubro de 2017. Aprovado em dezembro de 2017. 